\title{
Phenolic Contents and Antioxidant Activities of Persimmon and Red Beet Jams Produced by Sucrose Impregnation
}

\author{
Tugba Oksuz ${ }^{1}$, Ece Surek $^{2}, Z_{\text {Zeynep Tacer-Caba }}{ }^{1}$, Dilara Nilufer-Erdil $^{1, *}$ \\ ${ }^{1}$ Department of Food Engineering, Faculty of Chemical and Metallurgical, Istanbul Technical University, 34469, Maslak, Istanbul, Turkey \\ ${ }^{2}$ Department of Food Engineering, Faculty of Engineering, Izmir Institute of Technology, 35430, Urla, Izmir, Turkey
}

Copyright $(\underset{0}{2015}$ Horizon Research Publishing All rights reserved.

\begin{abstract}
This study aims to bring different perspective to literature by defining changes in TPC and AA of sucrose impregnation applied jams produced from high antioxidant potential fruit and vegetables. Total phenolic contents were determined by the Folin-Ciocalteau method and total antioxidant activities were determined with ABTS and DPPH radical scavenging methods for both fresh fruits and the jams produced. Major phenolic compounds such as catechin, gallic acid, caffeic acid, hesperidin and betanin were identified by High performance liquid chromatography. In respect of results; jam processing by means of sucrose impregnation was found to result in insignificant decreases in total phenolic contents for persimmon (35.4\%), however significant losses were observed for the red beet jam (49.9\%). According to DPPH results, as a result of jam processing, insignificant decreases (about 16\%) in antioxidant activity levels for persimmon was found whereas for sugar beet jam the reduction was found significant (43.4\%). According to ABTS data, jam processing was found to have negative effect on antioxidant activity only for the red beet.
\end{abstract}

Keywords Persimmon, Red Beet, Antioxidant, Phenolic Content, Jam, Sucrose Impregnation

\section{Introduction}

Polyphenols are widely distributed in many fruits, vegetables, teas and beverages and they exert potential health-promoting effects as antioxidants besides their antitumor and anti-carcinogenic effects. There are many studies in literature showing the inverse relation between the consumption of "vegetable food" and cancer or heart diseases [1]. The attention paid to compounds showing high antioxidant activity (AA), such as carotenoids, anthocyanins and recently betalains has increased [2].

Persimmon (Diospyros kaki L.) is an important plant used for several purposes such as to stop bleeding, paralysis treatment, frosbite and burns [3]. There are some studies showing that it has medical effects on haemostasis, constipation, hypertension, apoplexy and atherosclerosis. It is a good source of antioxidants, vitamins, polyphenols and dietary fibers. Persimmon leaves have flavonoid oligomers, tannins, phenols, organic acids, chlorophyll, vitamin $\mathrm{C}$ and caffeine. There are also significant compounds such as catechin, epicatechin, gallic acid, kaempferol and quercetin exerting high AA [3-5]. It is an important bioactive fruit and has higher AA than apple, grape, tomato, blueberry and strawberry [6].

The hypolipidemic and antioxidant effects of two different diets in rats fed with cholesterol were investigated and compared as $7 \%$ of whole dry persimmon and $7 \%$ of phenol-free dry persimmon diets [7]. According to the researchers' findings claimed that persimmon phenolics were positively influencing lipid levels The antioxidant effect of persimmon was primarily related with its phenolics [7].

Red beet (Beta vulgaris L.) includes specifically high amount of antioxidants. It contains betalains, which are significant natural food colorants, (composed of betacyanins and betaxanthins) and also many phenolic compounds such as ferulic acid conjugates, phenolic amides, and flavonoids $[8,9]$. The most significant betalain compound is betanin, which is a glycoside composed of glucose and betanidin. Beetroot has a red and purple color due to betacyanin and betanin. Betacyanin can decrease LDL cholesterol oxidation and is effective on cardiovascular diseases [8,9].

It is known that persimmon and red beet are rich in AA and many published in vitro studies showed the strong antiradical content and especially the AA of betalains from red beets [2]. However, their consumption is possible for only a few months of the year, since they are mostly consumed as a fresh fruit in Turkey. Persimmon is only marketable for 2-4 months by cold storage and red beet can be harvested in October and consumed for only 4 months. 
These two fruits have only a very limited shelf-life. Therefore, similar to many fruits and vegetables as they are seasonally available processing into products such as juice, jam, dried fruit, ice cream, etc. which may be good solutions to benefit from their health effects throughout the whole year. Therefore, determination of changes in phenolic contents and AA upon processing is necessary for the products obtained from those two sources to evaluate their bioactive potential more accurately.

Effects of several processes such as; harvesting, preparation and handling of fruits and vegetables on antioxidant status have been reported by many researchers [10]. Numerous researchers have specifically studied the effect of traditional jam processing on phenolic content and AA of fruit and vegetables [11-13]. Rababah et al., (2011) studied the effect of jam processing on strawberry, cherry, apricot, fig and orange and reported significant losses in total phenolics (about $69-93 \%$ changing according to the type of the fruit), antioxidant activity (11-39\%) and anthocyanins (60-99\%) in jams, while they showed only moderate losses during storage for five months [11]. In contrast, Kim and Zakour, (2006) comprised different cultivars of cherries, plums and raspberries and their results indicated that more than $73 \%$ total phenolics and more than $65 \%$ antioxidant capacity were retained after processing fruits into jams, although anthocyanins were almost lost completely [12]. Contradictory results available in literature emerged the trials of different or modified applications for jam processing.

Impregnation may be defined as replacing the gas and liquid of a material through the internal pores by using an external liquid. Fruits are practically suitable for this application because of their homogeneous tissues accelerating mass transfer [14-15]. Use of carbohydrates, particularly sucrose might be a beneficial alternative for jam processing since it is able to diffuse through the cell wall and stay between the wall and membrane parts of fruits [16]. This ability was previously used for stabilizing colorful pigments found in foods. The working mechanism was related with either the reversible inclusion complexes formed between cavities in cyclodextrin moieties of carbohydrate sources and smaller molecules (often phenolic substances) or loss of water in fruits since anthocyanin color is known to increase upon the removal of water [17].

Although it is suggested for enriching foods with nutrients/additives and also for a better sensorial quality in terms of taste, appearance and smell, sucrose impregnation had only a limited use for jam processing and mainly applied to anthocyanin rich fruits such as strawberries [14].

The main objective of this study is to determine total phenolic content (TPC) and AA of red beet and persimmon both when they are both fresh and processed into jams by means of sucrose impregnation application. The losses in traditional jam processing from the literature were compared with that of sucrose impregnated ones in this study.

\section{Materials and Methods}

\subsection{Materials}

Persimmon and red beet were obtained from a local market in Istanbul, Turkey. Chemicals were used in the study such as methanol, formic acid, trifluoroacetic acid (TFA), sodium carbonate, potassium persulfate, dipotassium hydrogen phosphate, potassium dihydrogen phosphate were obtained from Merck (Darmstadt, Germany). Gallic acid, Folin-Ciocalteu phenol reagent,

2,2-diphenyl-1-picrylhydrazyl (DPPH), acetonitrile were purchased from Sigma-Aldrich (Steinheim, Germany). 6-hydroxy-2,5,7,8-tetramethylchroman-2-carboxylic acid (Trolox) and

2,2'-azinobis-3-ethylbenzo-thiazoline-6-sulphonic acid diammonium salt (ABTS) were obtained from Fluka (Buchs, Switzerland) and Applichem (Darmstadt, Germany), respectively. HPLC standards such as gallic acid, catechin, caffeic acid, hesperidin and betanin were obtained from Extrasynthese (Genay, France).

\subsection{Methods}

\subsubsection{Preparation of Fruit Jams by Means of Impregnation}

Fruits were washed with tap water to remove dirt from their peels. Red beet chopped into small pieces and persimmon was pureed with a hand blender for jam processing. $350 \mathrm{~g}$ red beet and $300 \mathrm{~g}$ persimmon were impregnated in $700 \mathrm{~g}(1: 2 \mathrm{ratio}, \mathrm{w} / \mathrm{w})$ and $365 \mathrm{~g}$ (about 1:1 $\mathrm{w} / \mathrm{w}$ ) granulated sugar overnight, respectively, and boiled to about $88^{\circ} \mathrm{Bx}$ which was checked with a pocket refractometer. Samples were cooled to room temperature and filled into a glass jar. Sampling was done into plastic bags and stored at $-80^{\circ} \mathrm{C}$ before extraction. Samples were ground to a fine powder in liquid nitrogen by using a precooled grinder (IKA-Werke GmbH \& Co. KG, Staufen, Germany).

\subsubsection{Moisture Analysis}

To express the results in dry weight basis (DW), moisture content of samples was measured by using a vacuum oven method [18].

\subsubsection{Extraction of Phenolics}

One gram of each sample was weighed in test tubes under liquid nitrogen. $5 \mathrm{ml}$ of $75 \%$ methanol: water (v/v) solution with $0.1 \%$ formic acid was added into each tube. Samples were sonicated for $15 \mathrm{~min}$ in an ultrasonic bath (Ultrasonic Cleaner-VWR, PA, USA) and centrifuged (Andreas Hettich GmbH\&Co.KG, Tuttlingen, Germany) at $4000 \mathrm{rpm}$ at $4^{\circ} \mathrm{C}$. This was repeated 4 times until $20 \mathrm{ml}$ of solvent was used and extracts were stored at $-20^{\circ} \mathrm{C}$ until analysis [19].

\subsubsection{Determination of Total Phenolic Content and Antioxidant Activity}

TPC and AA analyses, by DPPH and ABTS radical 
scavenging methods, were carried out by using UV-visible spectrophotometer (Shimadzu, Kyoto, Japan). TPC was analysed by a modified Folin-Ciocalteu method [20]. According to the procedure, $100 \mu 1$ of extract or standard was mixed with $750 \mu$ of Folin-Ciocalteu reagent (diluted 1:10 with distilled water) and then $750 \mu \mathrm{l}$ sodium carbonate solution $(60 \mathrm{~g} / \mathrm{l})$ was added. After incubating for $90 \mathrm{~min}$, absorbance was measured at $725 \mathrm{~nm}$. The calibration curve was prepared by using gallic acid as standard and the results were expressed in mg gallic acid equivalents (GAE) per 100 $\mathrm{g}$ of DW. AA analysis by DPPH radical scavenging method was performed [21]. $100 \mu \mathrm{l}$ of extract or standard was added to $2 \mathrm{ml}$ of DPPH in methanol solution $(100 \mu \mathrm{M})$ in a test tube. After incubating for 30 minutes, the absorbance was measured at $517 \mathrm{~nm}$. The calibration curve was prepared by using Trolox and the results were expressed in mg Trolox equivalents (TEAC) per $100 \mathrm{~g}$ of DW.

ABTS radical scavenging method was performed as described by Miller and Rice-Evans [22], $100 \mu 1$ of extract or standard was added into $1 \mathrm{ml}$ of prepared ABTS reagent mixture and mixed for 15 seconds. After waiting for 45 seconds, absorbance was measured at $734 \mathrm{~nm}$. The calibration curve was prepared by using Trolox and the results were expressed in mg TEAC per $100 \mathrm{~g}$ of DW.

\subsubsection{Phenolic Profile and Betalain Identification by HPLC}

Major phenolic compounds and betalain were analyzed by using the HPLC-PDA method as described previously [19]. Standard calibration curves were prepared by using catechin, gallic acid, mallic acid, caffeic acid, hesperidin and betanin standards. Methanolic extracts were filtered through a $0.45-\mu \mathrm{m}$ membrane filter and $1 \mathrm{ml}$ of the filtered extract was placed into vials and analyzed in a Waters W600 HPLC system with PDA (Waters 996) detectors, for each sample. Luna C18 column (Phenomenex) was used as the stationary phase. The mobile phase was including solvent A, Milli-Q water with $0.1 \%(\mathrm{v} / \mathrm{v})$ TFA and solvent $\mathrm{B}$, acetonitrile with $0.1 \%(\mathrm{v} / \mathrm{v})$ TFA. A linear gradient was used as follows: at 0 min, $95 \%$ solvent $\mathrm{A}$ and $\% 5$ solvent $\mathrm{B}$; at $45 \mathrm{~min}, 65 \%$ solvent $\mathrm{A}$ and $35 \%$ solvent $\mathrm{B}$; at $47 \mathrm{~min}, 25 \%$ solvent $\mathrm{A}$ and $75 \%$ solvent $\mathrm{B}$; and at $54 \mathrm{~min}$ returns to initial conditions. The flow rate was $1 \mathrm{ml} / \mathrm{min}$. Detections were done at 280 , $312,360 \mathrm{~nm}$ for phenolic compounds, and at $520 \mathrm{~nm}$ for betalain. Identification was based on the retention times and characteristic UV spectra and quantification was done by external standard curves. All analyses were performed in triplicate.

\subsection{Statistical Analyses}

All of the results were reported as mean value \pm standard deviation. The results were analyzed statistically by using ANOVA and Duncan's New Multiple Range Test in SPSS 16.0 version at 0.05 significant level.

\section{Results}

Results of the spectrophometric assays were given in DW basis in Table 1. According to the results; TPC of the samples were changing between $276.70 \pm 0.08$ and $1863.65 \pm 0.03 \mathrm{mg} \mathrm{GA} / 100 \mathrm{~g}$ DW. Among two fruits and their jams, fresh red beet showed the highest TPC $(1863.65 \pm 0.03$ $\mathrm{mg} \mathrm{GA} / 100 \mathrm{~g}$ DW). Moreover, fresh red beet together with the red beet jam $(929.40 \pm 0.03 \mathrm{mg} \mathrm{GAE} / 100 \mathrm{~g} \mathrm{DW})$ revealed significantly higher TPC $(p<0.05)$ than fresh persimmon (428.62 $\pm 0.12 \mathrm{mg}$ GAE/100g DW) and persimmon jam (276.70 $\pm 0.08 \mathrm{mg}$ GAE/100g DW).

Among AA assays; results by DPPH radical were found to range between $61.12 \pm 0.02$ and $217.60 \pm 0.09 \mathrm{mg}$ TEAC/ $100 \mathrm{~g}$ DW. Persimmon had the highest AA $(217.60 \pm 0.09 \mathrm{mg}$ TEAC/100g DW) among all samples followed by its jam (183.74 $0.05 \mathrm{mg}$ TEAC/100g DW). Persimmon jam showed significantly higher $(\mathrm{p}<0.05)$ AA than red beet jam (61.12 $\pm 0.02 \mathrm{mg}$ TEAC/100g DW). Although fresh red beet possessed the highest TPC, it did not show the highest AA (108.30 $\pm 0.03 \mathrm{mg}$ TEAC/100g DW) according to DPPH radical scavenging method. ABTS radical scavenging activity results were found to be between $77.48 \pm 0.10$ and $500.17 \pm 0.19 \mathrm{mg}$ TEAC/100g DW. Fresh red beet was found to have the highest AA content $(500.17 \pm 0.19 \mathrm{mg}$ TEAC/100g DW) according to this method and therefore showed a similar trend with TPC results.

\section{Discussion}

TPC of all samples are given in Figure 1. Red beet had the highest level of phenolics. TPC decreased significantly $(49.9 \%)$ when red beets were processed into red beet jam $(\mathrm{p}<0.05)$. In contrast, reduction in TPC (about $35.4 \%$ ) when persimmon was processed into jam was found to be statistically insignificant $(\mathrm{p}>0.05)$.

Table 1. Total Phenolic Contents and Radical Scavenging Activities with $\mathrm{DPPH}$ and ABTS methods for fruits and jams

\begin{tabular}{|c|c|c|c|}
\hline Sample & $\begin{array}{c}\text { Total Phenolic } \\
\text { Content } \\
(\mathrm{mg} \mathrm{GA} / \\
100 \mathrm{~g} \mathrm{DW})\end{array}$ & $\begin{array}{c}\text { DPPH Radical } \\
\text { Scavenging } \\
\text { Activity } \\
\text { (mg TEAC } \\
/ 100 \mathrm{~g} \text { DW) }\end{array}$ & $\begin{array}{c}\text { ABTS } \\
\text { Radical } \\
\text { Scavenging } \\
\text { Activity } \\
(\mathrm{mg} \text { TEAC/ } \\
100 \mathrm{gDW})\end{array}$ \\
\hline Persimmon & $428.62 \pm 0.12 \mathrm{c}$ & $217.60 \pm 0.09 \mathrm{a}$ & $364.85 \pm 0.14 \mathrm{ab}$ \\
\hline $\begin{array}{c}\text { Persimmon } \\
\text { Jam }\end{array}$ & $276.70 \pm 0.08 \mathrm{c}$ & $183.74 \pm 0.05 \mathrm{a}$ & $105.57 \pm 0.05 \mathrm{ab}$ \\
\hline Red Beet & $1863.65 \pm 0.03 \mathrm{a}$ & $108.30 \pm 0.03 \mathrm{~b}$ & $500.17 \pm 0.19 \mathrm{a}$ \\
\hline Red Beet Jam & $929.40 \pm 0.03 \mathrm{~b}$ & $61.12 \pm 0.02 \mathrm{c}$ & $77.48 \pm 0.10 \mathrm{~b}$ \\
\hline
\end{tabular}

Previously other researchers have studied on the TPC of red beets and persimmon as fresh fruits or fruit juices. Fu et al. (2011) analyzed TPC of 62 fruits, including persimmon. They found persimmon as one of the fruits with strongest antioxidant activity among the tested fruits and determined its TPC as $112.09 \pm 4.60 \mathrm{mg} \mathrm{GAE} / 100 \mathrm{~g} \mathrm{FW}$ [4]. In another study; analysis of TPC by the Folin-Ciocalteu method for 23 commercially vegetable juices such as carrot, tomato, beetroot, mixed vegetable, mixed fruit and vegetable juices 
showed that beetroot juice had the highest TPC value as much as $160 \mathrm{mg} / 100 \mathrm{~g} \mathrm{FW}$, which was lower than the result obtained for the red beet (in dry matter basis) in this study, as expected [26]. Chen et al., (2008) compared total and individual phenolics of persimmon, tomato, grape and apple. The phenolic content of persimmon was found to be the highest value ( $168.15 \pm 0.12 \mathrm{mg} \mathrm{GAE} / 100 \mathrm{~g} \mathrm{DW})$, which was lower than the value measured in this study $(428.62 \pm 0.12$ $\mathrm{mg} \mathrm{GAE} / 100 \mathrm{~g}$ DW) [23]. Suzuki et al. (2005) determined the highest value of TPC for astringent persimmon as 84.6 $\mathrm{mg}$ catechin equivalents/100g DW [24]. Gorinstein et al. (1999) measured TPC of persimmon as $1.45 \mathrm{mg} / 100 \mathrm{~g} \mathrm{FW}$ [25]. Therefore, the content of total phenolics measured in fruits may be different due to differences in fruit varieties and methods of analysis [23].

When the effect of jam processing on phenolics is evaluated sharp decreases in TPC were notified. The study [11] monitored changes in TPC after fruits (strawberries, cherries, apricots, figs and oranges) were processed into jams. Jams were produced by means of cooking the fruits with sugar and other ingredients such as pectin and citric acid, that might be so called as "traditional" jam processing. According to their findings, the extents of decreases in TPC after processing into jam were as much high as $93,88,73,76$ and $69 \%$ in these fruits (strawberries, cherries, apricots, figs and oranges), respectively. They reported that the reduction in TPC during jam processing could be related with the decrease in total content of one certain phenolic acid such as ellagic acid or could be related with the disruptions in cell structure during fruit processing into jam [11]. Results of this study revealed that sucrose impregnation application in which fruit is left with sugar before cooking was a promising method for preserving phenolics since the extent of TPC losses were significantly lower than the ones obtained for traditional jam processing which involves boiling fruits with a sugar solution. Watanabe et al. (2011), summarized the effect of sucrose impregnation as a total effect of different phases. During the first phase, the sucrose was promptly transferred from the outer pericarp to unoccupied positions of the fruit, to where it could easily move through the fruit. Afterwards, the rate of transfer slowed down as the empty spaces were filled with sucrose from the solution [14]. Therefore, it might have reduced the disruptions in the cell structure in comparison to the traditional jam processing. It is difficult to precisely understand the underlying mechanisms for the observed changes in polyphenolic content in osmotically dehydrated samples. Strawberry cells submitted to osmotic stress were reported to induce anthocyanin and some phenolic compound synthesis [27].

DPPH radical scavenging activity results are presented in Fig. 2.Significant difference $(p<0.05)$ was obtained between red beet and persimmon by means of DPPH radical scavenging activity. According to DPPH method results, after processing into jam, AA for persimmon was found to display an insignificant decrease (15.6\%) whereas for red beets statistically significant reductions $(\mathrm{p}<0.05)$ were obtained (43.6\%). As shown in Fig. 3, red beet jam showed lower AA by ABTS method than other samples similar to the trend of DPPH results. On the other hand, jam processing did not affect AA of persimmon $(\mathrm{p}>0.05)$. However, jam processing decreased AA of red beet significantly $(84.5 \%)$. Changes in AA between two different fruits were more distinct, probably because of the differences in their phenolics. For example, since betanin in red beet has a low heat stability, the extent of decrease in its AA is significant $(p<0.05)$. Phenolic acids are known to present differences for their heat sensitivity and phenolics of persimmon were indicated to be resistant to heat. Besides some carotenoids certain phenolic compounds such as $p$-coumaric acid, gallic acid, epicatechin, ferulic acid, vanilic acid and protocatechuic acid are reported to be available in persimmon fruits [28]. Losses in AA of selected fruit jams of strawberries, cherries, apricots, figs and oranges after traditional jam processing, were $24 \%, 13 \%, 41 \%, 39 \%$ and $11 \%$, respectively [11]. Watanabe et al. (2011) studied jam processing by means of sucrose impregnation in anthocyanin-rich fruits and reported that anthocyanins were better protected after this application and their AA was also higher than the traditional jam processing [14]. Therefore, sucrose impregnation seems effective in preserving certain types of phenolics.

\section{TPC}

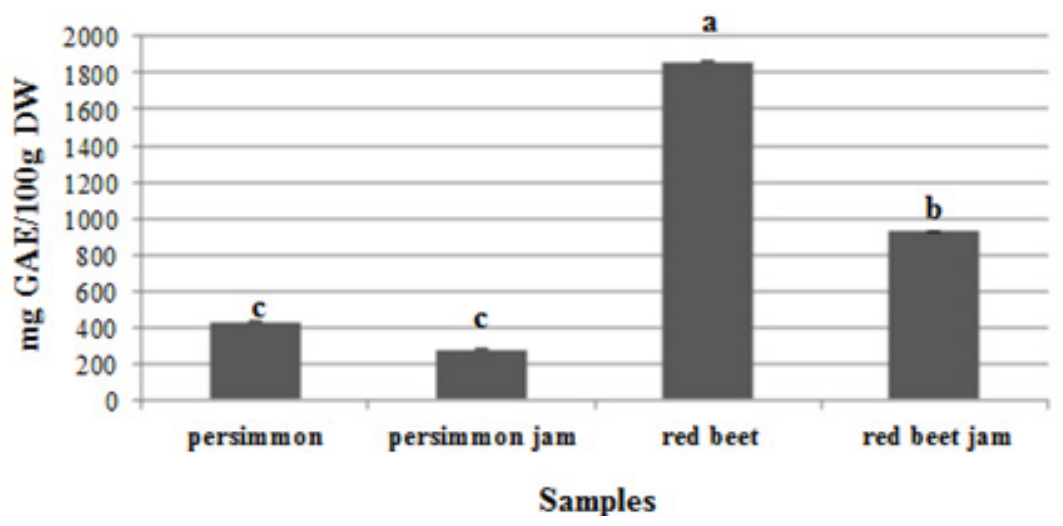

a,b,c Different letters indicate significant difference $(\mathrm{p}<0.05)$.

Figure 1. TPC results of all samples in DW basis 


\section{DPPH}

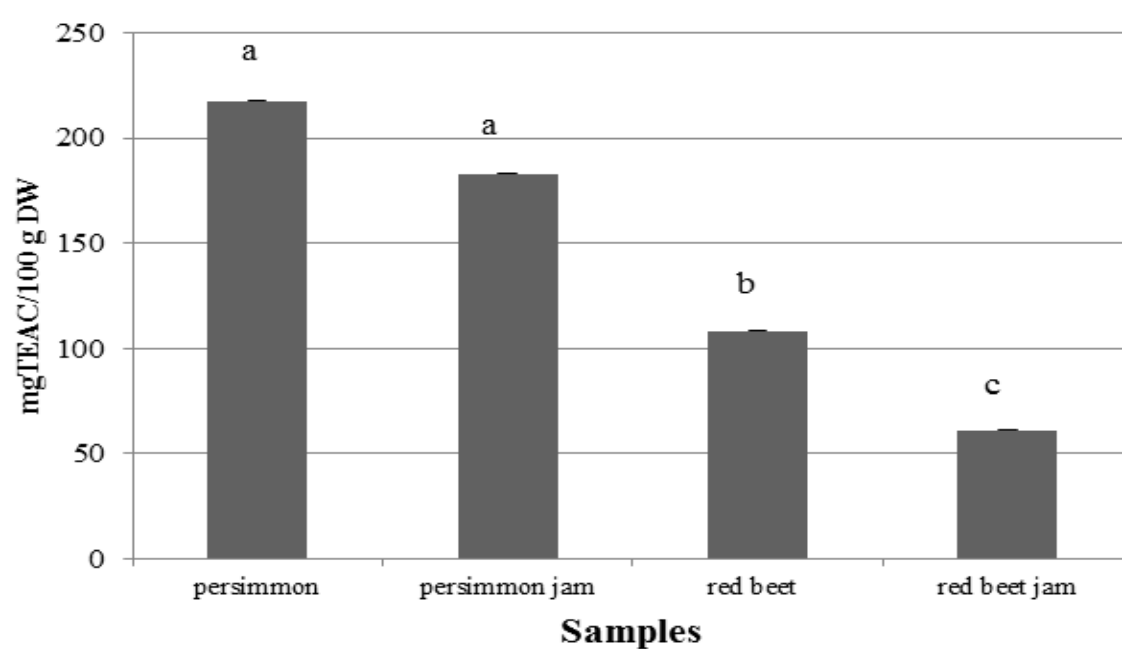

a,b,c Different letters indicate significant difference $(\mathrm{p}<0.05)$.

Figure 2. DPPH radical scavenging activity results of all samples in DW basis.

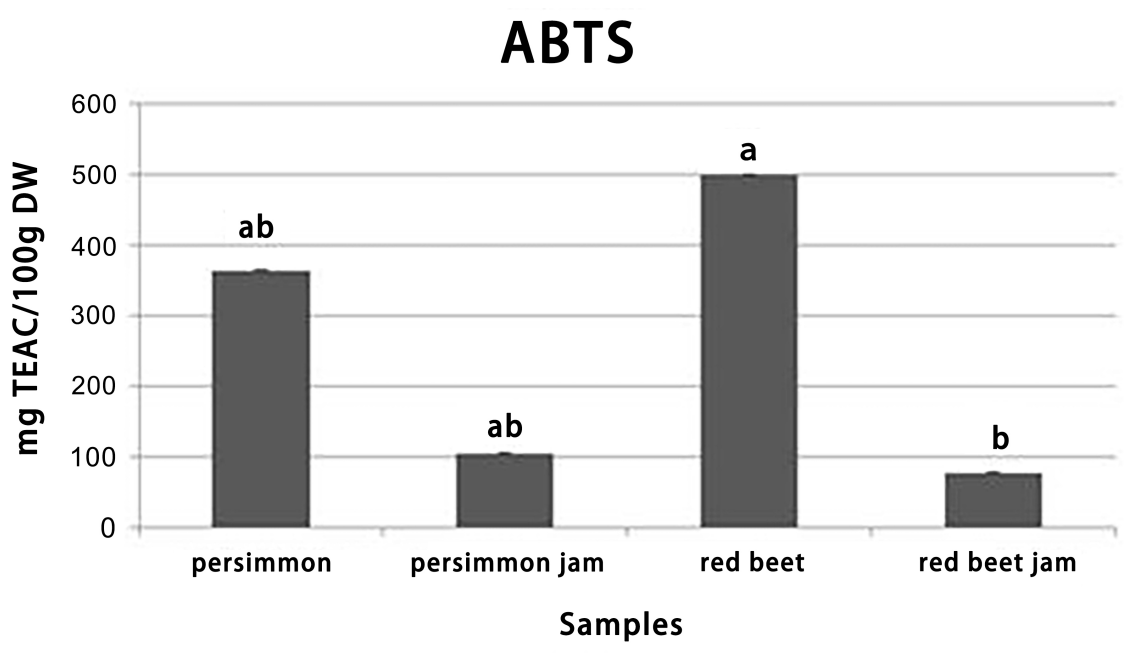

a,b,c Different letters indicate significant difference $(\mathrm{p}<0.05)$

Figure 3. ABTS radical scavenging activity results of all samples in DW basis.

Identification of betalains or major phenolic compounds in fresh red beet, red beet jam, persimmon and persimmon jam by HPLC were shown in, Fig. $4 \mathrm{a}$ and $4 \mathrm{~b}$, Fig. $5 \mathrm{a}$ and $5 \mathrm{~b}$. Gallic acid was the dominant phenolic component in persimmon. Besides gallic acid; catechin and caffeic acid were also identified in persimmon. In persimmon jam, hesperidin, which is a glycosidic flavonone was also found. Gallic acid $(4.16 \mathrm{mg} / 100 \mathrm{~g})$, catechin $(10.34 \mathrm{mg} / 100 \mathrm{~g})$, caffeic acid $(0.30 \mathrm{mg} / 100 \mathrm{~g})$ were detected in fresh persimmon. Gallic acid (3.09 $\mathrm{mg} / 100 \mathrm{~g})$, catechin $(3.79$ $\mathrm{mg} / 100 \mathrm{~g}$ ) were found in persimmon jam; however caffeic acid was not detected. In respect of HPLC results, a significant difference was found between the fresh persimmon and persimmon jam phenolic compounds. In persimmon jam, gallic acid and catechin were lost at $25.9 \%$ and $63.4 \%$ levels, respectively.

Chen et al. (2008) found different levels of phenolic compounds in fresh persimmon; gallic acid $(19.11 \mathrm{mg} / 100 \mathrm{~g})$, catechin $(5.81 \mathrm{mg} / 100 \mathrm{~g})$, caffeic acid $(2.83 \mathrm{mg} / 100 \mathrm{~g})$ [22]. Differences between the results can be related to different varieties of persimmon.

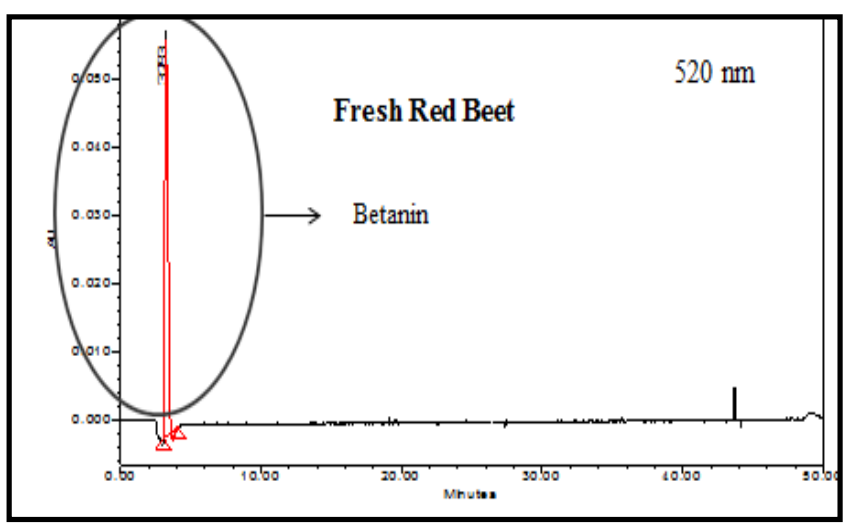

Figure 4a. Betalains of fresh red beet 


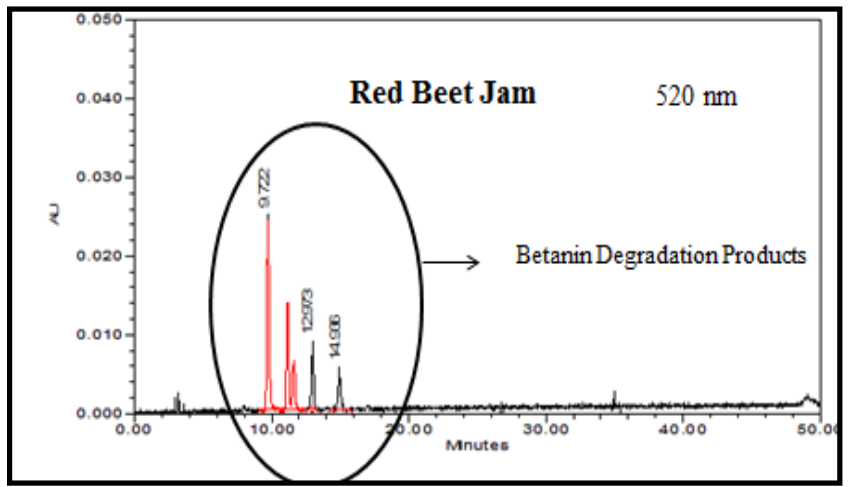

Figure 4b. Betalains of red beet jam

The outstanding component in red beet was betanin, which had high AA but low heat stability. In red beet other phytochemicals such as 4-hydroxy benzoic acid, cinnamic acid, vanillic, chlorogenic, trans-ferulic acid and caffeic acid were also determined by other researchers [29]. In red beet jam it was converted into other forms such as betanidin and its degradation products as shown in Fig. 4a and 4b. Herbach et al. (2004) studied thermal effect on red beet color and pigments. According to their study they also defined the major component as betanin [30]. After treatment at a high temperature $\left(85^{\circ} \mathrm{C}\right)$ for an hour, there were four degradation components (betanin, isobetanin, neobetanin, vulgaxanthin) as mentioned in our study.

\section{Conclusions}

In conclusion; two fruits in concern were affected differently from jam processing. This might be related with the different phytochemicals present in those fruits, their variable antioxidant activities and differences in those components' stability to heat and processing. Results revealed that persimmon may be a good raw material for jam processing with its potential and preserved phenolics and AA when compared with other jams available in the market. Sucrose impregnation application is conserving the phenolic contents and AA, so this application is recommended instead of boiling with sugar application that is traditionally applied during jam processing.

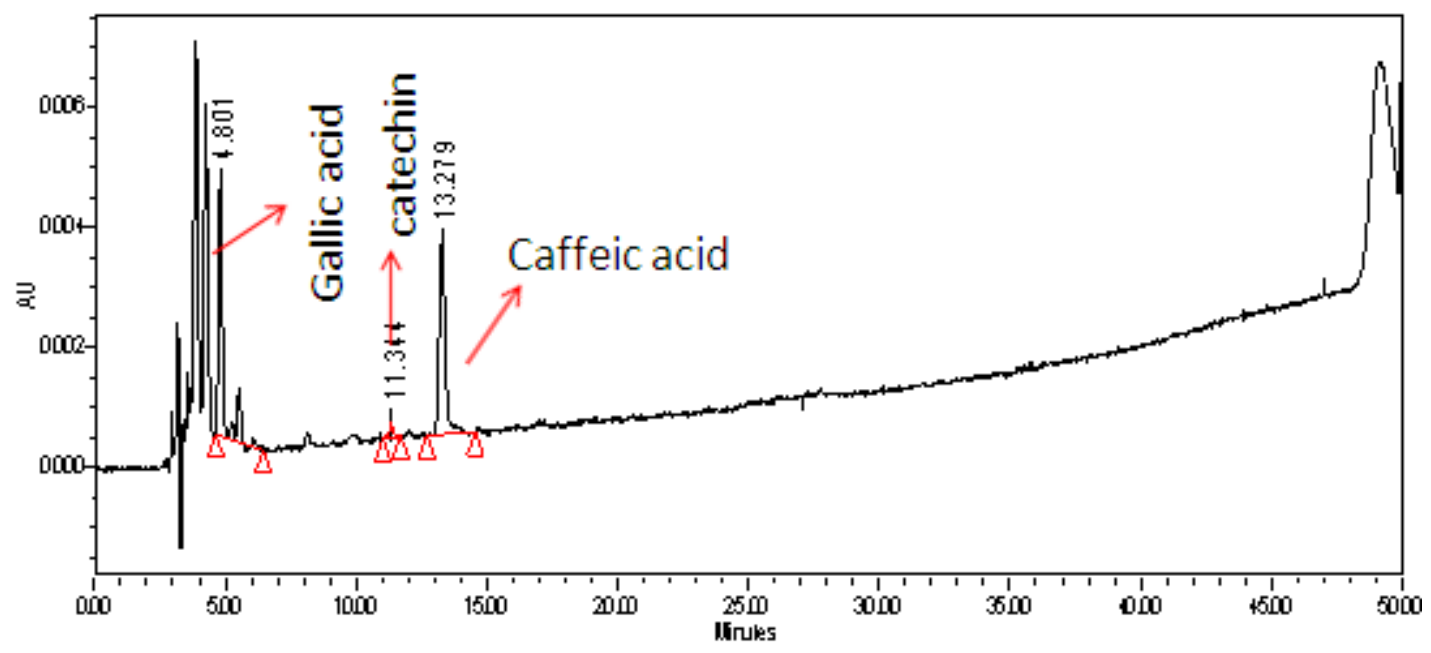

Figure 5a. Phenolic compounds of fresh persimmon

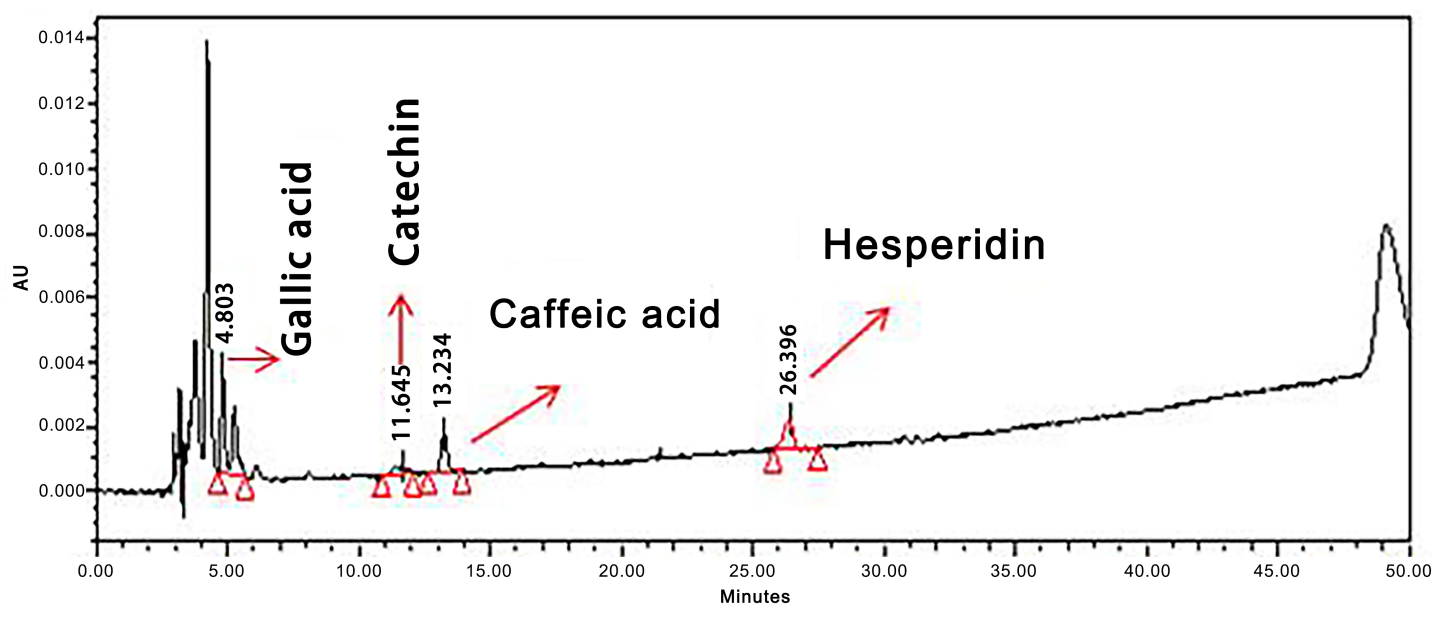

Figure 5b. Phenolic compounds of persimmon jam 


\section{REFERENCES}

[1] J.M. Genkinger, E.A. Platz, S.C. Hoffman, G.W. Comstock, K.J. Helzlsouer. Fruit, vegetable, and antioxidant intake and all-cause, cancer, and cardiovascular disease mortality in a community-dwelling population in Washington County, Maryland. American Journal of Epidemiology. 160, 1223-33, 2004.

[2] T. Frank, F.C. Stintzing, R. Carle, I. Bitsch, D. Quaas, G. Straß, R. Bitsch, M. Netzel. Urinary pharmacokinetics of betalains following consumption of red beet juice in healthy humans, Pharmacological Research. 52, 290-297, 2005.

[3] L. Sun, J. Zhang, X. Lu, L. Zhang, Y. Zhang. Evaluation to the antioxidant activity of total flavonoids extract from persimmon (Diospyros kaki L.) leaves, Food and Chemical Toxicology, 49, 2689-2696, 2011.

[4] L. Fu, B.T. Xu, X.R. Xu, R.Y. Gan, Y. Zhang, E.Q. Xia, H.B. Li. Antioxidant capacities and total phenolic contents of 62 fruits, Food Chemistry, 129, 345-350, 2011.

[5] S. Gorinstein, G.W. Kulasek, E. Bartnikowska, M. Leontowicz, M. Zemser, M. Morawiec, S. Trakhtenberg. The influence of persimmon peel and persimmon pulp on the lipid metabolism and antioxidant activity of rats fed cholesterol, Journal of Nutritional Biochemistry, 9, 223-227, 1998.

[6] P.M. Li, G.-R. Du, F.-W. Ma. Phenolics concentration and antioxidant capacity of different fruit tissues of astringent versus non-astringent persimmons, Scientific Horticulture, 129, 710-714, 2011.

[7] S. Gorinstein, G.W. Kulasek, E. Bartnikowska, M. Leontowicz, M. Zemser, M. Morawiec, S. Trakhtenberg. The effects of diets, supplemented with either whole persimmon or phenol-free persimmon, on rats fed cholesterol, Food Chemistry, 70, 303-308, 2000.

[8] P.C. Wootton-Beard, L. Ryan. A beetroot juice shot is a significant and convenient source of bioaccesible antioxidants, Journal of Functional Foods, 3, 329-334, 2011.

[9] P.C. Wootton-Beard, A. Moran, L. Ryan. Stability of the total antioxidant capacity and total polyphenol content of 23 commercially available vegetable juices before and after in vitro digestion measured by FRAP, DPPH, ABTS and Folin-Ciocalteu methods, Food Research International, 44, 217-224, 2011.

[10] M.G. Lindley. The impact of food processing on antioxidants in vegetable oil, fruits and vegetables, Trends in Food Science and Technology, 9, 336-340, 1998.

[11] T.M. Rababah, M.A. Al-Mahasneh, I. Kilani, W. Yang M.N. Alhamad K. Ereifeja, M. Al-u'datta. Effect of jam processing and storage on total phenolics, antioxidant activity, and anthocyanins of different fruits. Journal of the Science of Food and Agriculture, 91, 1096-1102, 2011.

[12] D.O. Kim, O.I. Padilla-Zakour. Jam Processing Effect on Phenolics and Antioxidant Capacity in Anthocyanin-rich Fruits: Cherry, Plum, and Raspberry, Journal of Food Science, 69(9), 2004

[13] Y. Amakura, Y. Umino, S. Tsuji, and Y. Tonogai. . Influence of Jam Processing on the Radical Scavenging Activity and
Phenolic Content in Berries. Journal ofAgricultural and Food Chemistry, 48, 6292-6297, 2000.

[14] Y. Watanabe, K. Yoshimoto, Y. Okada, M. Nomura. Effect of impregnation using sucrose solution on stability of anthocyanin in strawberry jam. LWT - Food Science and Technology 44, 891-895, 2011.

[15] H., Hújica-Paz, A. Vaidez-Fragoso, A. López-Malo, E. Palou, J. Welti-Chanes. Impregnation and osmotic dehydration of some fruits: effect of the vacuum pressure and syrup concentration. Journal of Food Engineering, 57, 305-314, 2003

[16] M.G. Isse, H. Schubert. Osmotic dehydration of mango: mass transfer betweenmango and syrup. In Proc. of 4th World Congress of Chemical Engineering, (ed. Behrens, D.). Dechema, Frankfurt, pp. 738-745.

[17] C.E. Lewis, J.R.L. Walker. Effect of polysaccharides on the colour of anthocyanins. Food Chemisrry, 54, 315-3I9, 1995.

[18] Anon., TS 1129 Fruit and vegetable products-determination of dry matter by drying azeotropic distillation, Turkish Standards Institute, Ankara, 1998, pp. 1-3.

[19] E. Capanoglu, J. Beekwilder, D. Boyacioglu, R. Hall, R.D. Vos. Changes in antioxidant and metabolite profiles during production of tomato paste, Journal of Agricultural and Food Chemistry, 56, 964-973, 2008.

[20] Y.S. Velioglu, G. Mazza, L. Gao, B.D. Oomah. Antioxidant activity and total phenolics in selected fruits, vegetables and grain products, Journal of Agricultural and Food Chemistry, 46, 4113-4117, 1998.

[21] S. Rai, A. Wahile, K. Mukherjee, B.P. Saha, P.K. Mukherjee. Antioxidant activity of Nelumbo nucifera (sacred lotus) seeds. Journal of Ethnopharmacology, 104, 322-327, 2006.

[22] N.J. Miller, C.A. Rice-Evans. Factors influencing the antioxidant activity determined by ABTS radical cation assay, Free Radical Research, 26, 195-199, 1997.

[23] X.N. Chen, J.E. Fan, X. Yue, X.R. Wu, L.T. Li. Radical scavenging activity and phenolic compounds in persimmon (Diospyros kaki L. Cv. Mopan), Journal of Food Science, 73, 24-28, 2008.

[24] T. Suzuki, S. Someya, F. Hu, M. Tanokura. Comparative study of catechin compositions in five Japanase persimmons (Diospyros kaki), Food Chemistry, 93, 149-152, 2005.

[25] S. Gorinstein, M. Zemser, R. Haruenkit, R. Chuthakorn, F. Grauer, O, Martin-Belloso, S. Trakhtenberg. Comparative content of total polyphenols dietary fiber in tropical fruits and persimmon, Journal of Nutritional Biochemistry, 10, 367-371, 1999.

[26] P.C. Wootton-Beard, L. Ryan. Improving public health?: The role of antioxidant-rich fruit and vegetable beverages, Food Research International, 44, 3135-3148, 2011.

[27] Suzuky, M. Enhancement of anthocyanin accumulation by high osmotic stress and low $\mathrm{pH}$ in grape cells (Vitis hybrids), Journal of Plant Physiology, 147, 152-155, 1995.

[28] S. Gorinstein, Z. Zachwieja, M. Folta, H. Barton, J. Piotrowicz, M. Zemser,M. Weisz,S. Trakhtenberg, O. Martın-Belloso. Comparative contents of dietary fiber, total phenolics, and minerals in persimmons and apples. Journal of Agricultural and Food Chemistry, 49, 952-957,2001. 
[29] K. Ravichandran, A.R. Ahmed, D. Knorr, I. Smetanska. The effect of different processing methods on phenolic acid content and antioxidant activity of red beet. Food Research International, 48, 16-20, 2012.
[30] K.M. Herbach, F.C. Stintzing, R. Carle. Impact of thermal treatment on color and pigment pattern of red beet (Beta vulgaris L.), Food and Chemical Toxicology, 69, 491-498, 2004. 